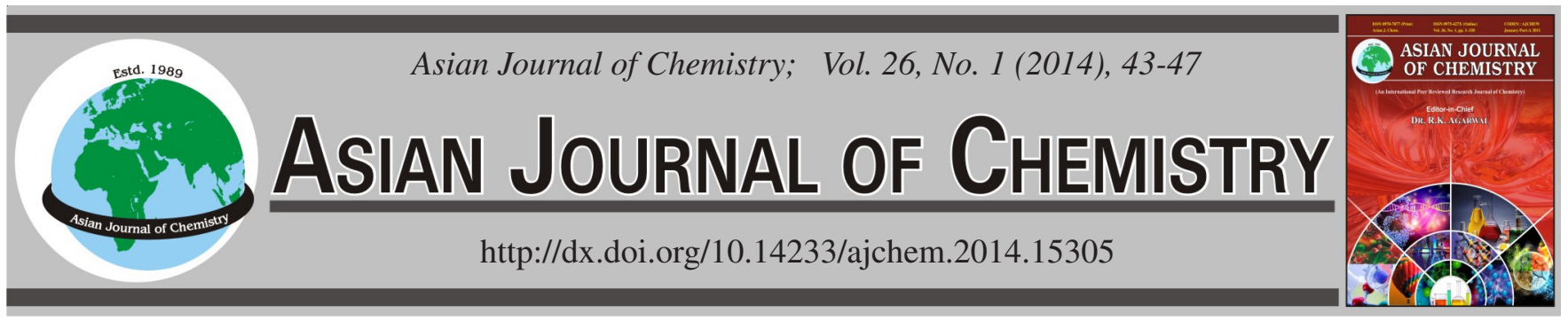

\title{
Adsorption Studies of Removal of Indigo Caramine Dye from Water by Formaldehyde and Urea Treated Cellulosic Waste of Citrus reticulata Peels
}

\author{
RABIA REHMAN", JAVARIA ZAFAR and HiNA NiSAR
}

Institute of Chemistry, University of the Punjab, Lahore-54590, Pakistan

*Corresponding author: Fax: +92 42 99230998; Tel: +92 42 99230463, Ext: 870; E-mail: grinorganic@yahoo.com

\begin{abstract}
The Citrus reticulata (orange) peels has been employed as adsorbents for removing inorganic and organic pollutants from wastewater extensively due to its low cost and eco-friendly nature. This research work concerns with the study of comparative removal of Indigo carmine dye from water using simple, formaldehyde and urea treated Citrus reticulata peels. The effect of adsorption parameters were investigated and maximum sorption capacity was obtained from Langmuir isotherm model at optimized conditions, i.e.: 5.90 , 14.79 and $71.07 \mathrm{mg} \mathrm{g}^{-1}$ for simple, formaldehyde treated and urea treated Citrus reticulata peels, respectively. Feasibility of process is indicated by the values of separation factor, Gibb's free energy and adsorption intensity ' $n$ '. The results of present study indicate that Citrus reticulata peels has inherited a lots of capacity for removing anthraquinone type of dyes, which can be further improved by treating with formaldehyde or urea in economical way.
\end{abstract}

Keywords: Citrus reticulata peels, Indigo carmine dye, Chemical modification, Isothermal study.

\section{INTRODUCTION}

Development of industries have large impact on environment. Many industries used dyes which contains much organic and inorganic colour causing compound. Fraction of dye lost in wastewater during dye-processing is $50 \%$ of dye used, due to their low fiber fixation value $\mathrm{e}^{1,2}$. Even $1 \mathrm{ppm}$ of dye in water make it non-suitable for human use ${ }^{3}$. Dye can also disturb marine life and plants because they reduced the sunlight penetration in water. They are carcinogenic and cause a detrimental effect on human beings, such as liver, brain, central nervous system, reproductive system etc..$^{4-6}$. The removal of dye from water is necessary because its small amount is very toxic and dangerous ${ }^{7}$. Many technique have been used to eradicate these pollutant from wastewater, like photochemical oxidation, coagulation, membrane filtration, electro-chemical and bacteriological degradation, etc $^{8}$. Wastewater released from textile contain organic compound, heavy metal, total dissolve solid, PCBs, surfactant, COD, BOD, salts ${ }^{9,10}$.

Dyes are usually categorized into cationic, anionic and non-ionic. Generally cationic dyes are basic in nature, whereas anionic dyes are acidic. Anionic dyes depend on the negatively charge ion ${ }^{11}$. They contain many compound, which have characteristic difference in structures (like: anthraquinone, triphenyl-methane, azoic and nitro dyes). Anthraquinonic types are more lethal, because of non-degradable nature ${ }^{12}$. They are used to dye synthetic fibers like modified acrylic, silk, polyamide and polypropylene. Their water soluble tendency is greater, but have a destructive effect on living things, because they have organic sulphonic acid group ${ }^{13}$.

The adsorption of anionic dyes using different adsorbents have studied by many researchers using bentonite, ammonium functionalized MCM 41, plant leaves, seeds, pine cone and bagasse ash ${ }^{14-17}$. The agricultural waste used in last few years has been low cost and the available adsorbent used for sorption of anionic/acidic dyes such as mango seeds, soymeal, rice/ wheat husk and bamboo ${ }^{11,12,18}$.

In this research work, Citrus reticulatapeels was used to remove Indigo carmine dye. This dye is a $\mathrm{pH}$ indicator, structure is given in Fig. 1. At pH 11.4, it exists in blue colour while at 13, it exists in yellow colour. It is also a redox indicator, on reduction it turns into yellow colour. It is used as food colourant in USA. It is also used as a dye in the formation of capsules, obstetrics and help to detect amniotic fluid leaks. If it is inhaled it is harmful to the respiratory tract and causes skin and eye irritations ${ }^{19-21}$. Citrus reticulata (common known as Kinnow or orange) belongs to plant family Rutaceae, usually reach a height of 25 feet on average with a greater spread. Pakistan is the one of the leading producer in the world and produces almost $95 \%$ of the total Kinnow production of the world. In traditional Ayurvedic herbal medicines, the dried peels of Citrus reticulata fruit is used to treat abdominal distension and reduce phlegm by enhancing digestion ${ }^{22-24}$. 


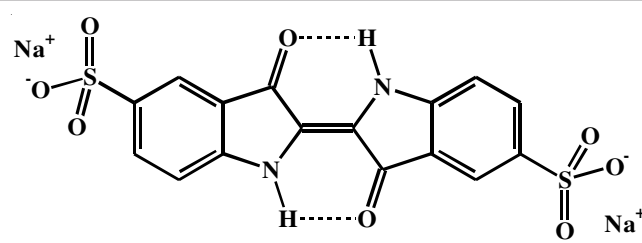

Fig. 1. Indigo Carmine (IUPAC name: 3,3'-dioxo-2,2'-bis-indolyden-5,5'disulfonic acid disodium)

\section{EXPERIMENTAL}

Indigo carmine [chemical formula $\mathrm{C}_{16} \mathrm{H}_{8} \mathrm{~N}_{2} \mathrm{O}_{8} \mathrm{~S}_{2} \mathrm{Na}_{2}$, m.w. $\left.=466.36 \mathrm{~g} / \mathrm{mol}, \lambda_{\max }=610 \mathrm{~nm}\right], \mathrm{HCl}, \mathrm{NaOH}$, urea and formaldehyde used in this research work (obtained from Fluka and Riedel-de Haen). pH meter (HANNA pH 211), spectrophotometer (Spectro UVD-3500, Labomed),Scanning Electron Microscope (SEM) S2700 Hitachi, Japan and FT-IR spectrometer (Perkin Elmer, ATR) were used for analysis. Dye stock solution was synthesized by dissolving its $1 \mathrm{~g} / \mathrm{L}$ of water (double distilled) and afterward diluted according to experimental needs.

Preparation of biosorbents: Fresh oranges (Citrus reticulata) were collected from local gardens of Lahore (Pakistan) and washed. Their peels were removed and dried in sunlight for a week. Then they were placed in oven at $70{ }^{\circ} \mathrm{C}$ for $4 \mathrm{~h}$. For chemical treatment, $100 \mathrm{~g}$ chopped, dried peels were soaked in $500 \mathrm{~mL}$ of $20 \%$ formaldehyde and $10 \%$ urea solutions separately for $3 \mathrm{~h}$. Then they were filtered and dried in air after covering with cloth to prevent contaminations for 3 days. For complete removal of moisture, they were kept in oven at $70^{\circ} \mathrm{C}$ for $4 \mathrm{~h}$. All these dried samples of simple (S.B), formaldehyde treated (F.T.B) and urea treated (U.T.B) Citrus reticulate peels were ground using electric grinder (Ken-Wood) and sieved through 50 mesh ASTM (297 microns). They were stored in plastic jars separately.

Adsorption studies: Following factors were studied in their respective ranges as followed in batch mode one after another, keeping one factor variable at a time and others constant: contact time interval (10-70 $\mathrm{min})$, dye solution $\mathrm{pH}$ (1-10), adsorbent dosage (0.3-3.0 g) and temperature (20$70{ }^{\circ} \mathrm{C}$ ). Constant mixing of the solution was provided by a agitating at $100 \mathrm{rpm}$. After adsorption, the adsorbent was separated from the solution and remaining concentration of dye was determined spectrometricallyat $\lambda_{\max }=610 \mathrm{~nm}$. The percentage adsorption of dye was determined by eqn. $1^{25}$ :

$$
\text { Removal }(\%) \text { of dye }=\frac{\mathrm{C}_{\mathrm{o}}-\mathrm{C}_{\mathrm{e}}}{\mathrm{C}_{\mathrm{o}}} \times 100
$$

The volume (V) of dye solution used in various steps was $0.05 \mathrm{~L}$ and initial concentration of dye ' $\mathrm{C}_{\mathrm{o}}$ ' was $25 \mathrm{mg} / \mathrm{L}$. For determining mechanism of removal of dye and feasibility of process, isothermal modeling of equilibrium data was done. Batchwise adsorption of dye was performed by using all the optimized conditions of various parameters on dye solutions with concentration ranges $30-80 \mathrm{mg} / \mathrm{L}$. Then after quantifying remaining concentration of dye " $\mathrm{C}_{\mathrm{e}}$ " adsorption capacities ' $\mathrm{q}$ ' was calculated by eqn. 2 :

$$
q=\frac{\left(C_{0}-C_{e}\right) V}{m}
$$

Langmuir and Freundlich models were applied on equilibrium data using their straight line eqns. 3 and 4 , respectively:

$$
\begin{gathered}
\log q=\log K_{F}+\frac{1}{n} \log C_{e} \\
\frac{1}{q}=\frac{1}{b_{m} C_{e}}+\frac{1}{q_{m}}
\end{gathered}
$$

here, ' $\mathrm{q}_{\mathrm{m}}$ ' and ' $\mathrm{b}$ ' are Langmuir parameters, whereas ' $\mathrm{K}_{\mathrm{F}}$ ' and ' $n$ ' are Freundlich parameters. Their values were determined by regression analysis of linear plots of respective isotherms. Experiments were repeated thrice and average values were used for calculations. Basic assumption of Langmuir model is that chemisorption of adsorbate occurs in monolayer fashion on adsorbent surface in homogenous way and there are no side interactions between adsorbed species molecules, whereas Freundlich model assumes multilayer physiosorption of adsorbate species on heterogeneously distributed binding sites on adsorbent surface. Feasibility of process is determined by separation factor, ' $R_{L}$ ' and Gibb's free energy ' $\Delta G^{\circ}$ ', which are determined by eqns. 5 and 6 , respectively:

$$
\begin{aligned}
\mathrm{R}_{\mathrm{L}} & =\frac{1}{\left(1+\mathrm{bC}_{\mathrm{o}}\right)} \\
\Delta \mathrm{G}^{\mathrm{o}} & =-\mathrm{RT} \ln \mathrm{K}
\end{aligned}
$$

here, ' $\mathrm{K}$ ' is the reciprocal of Langmuir constant ' $b$ '. $\mathrm{R}_{\mathrm{L}}$ value less than zero indicate unfavorable process, whereas in between zero to unity indicate favorable process ${ }^{26,27}$.

\section{RESULTS AND DISCUSSION}

Characterization of biosorbents: Citrus reticulata peels mostly consists of cellulosic material having reactive hydrogen atom. Formaldehyde undergoes addition reaction with compounds containing reactive hydrogen atom to form methylol derivatives (Fig. 2). Whereas hydroxyl groups of carboxylic acids or alcohols present in Citrus reticulate peels interact with urea forming condensation product as shown in Fig. 3. These mechanisms were also supported by FT-IR analysis as summarized in Table-1. FT-IR spectrum of Citrus reticulata peels indicated the presence of $\mathrm{O}-\mathrm{H}$ groups by broad peak at 3416 $\mathrm{cm}^{-1}$. In F.T.B, this peak is shifted to $3429 \mathrm{~cm}^{-1}$ supporting the possibility of chemical mechanism (Fig. 2). While this peak is vanished and a new peak at $3791 \mathrm{~cm}^{-1}$ is appeared in U.T.B, supporting second mechanism shown in Fig. 3. Other functional groups peaks values indicated the occurrence of carbonyl, ether and ester groups, that can interact better with acidic dye after protonation in acidic $\mathrm{pH}$ range. Further surface analysis were done by taking micrographs with scanning electron micro-

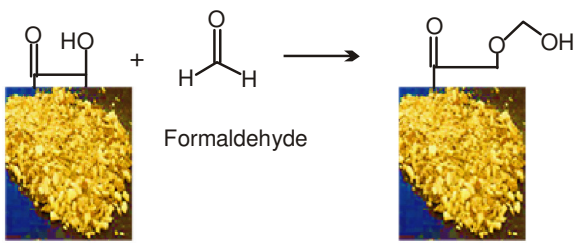

Citrus reticulata peels Formaldehyde treated Citrus reticulata peels

Fig. 2. Possible mechanism of formaldehyde treatment on Citrus reticulata peels 


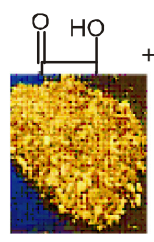

Citrus reticulata peels

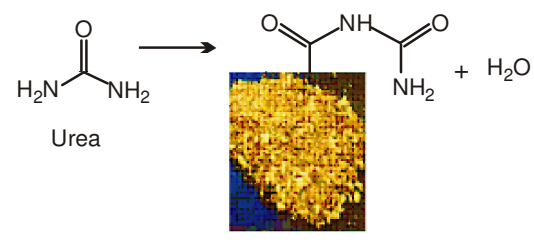

Urea modified Citrus reticulata peels
Fig. 3. Possible mechanism of urea treatment on Citrus reticulata peels

scope as given in Fig. 4. It is evident from Fig. 4 that after chemical modication with formaldehyde/urea, Citrus reticulata peels surface become more rough, uneven with visible pores and canals of irregular shapes permeating into the inner particle structure. These pores were produced after chemical modification, which in turns help in physisorptive removal of Indigo caramine dye $\mathrm{e}^{20-24}$.

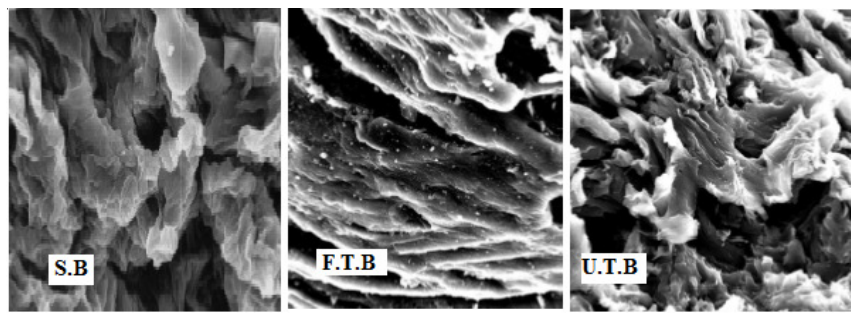

Fig. 4. SEM images of simple and chemically treated Citrus reticulata peels

\section{Adsorption parameters}

Contact time: Its effect on adsorption of Indigo carmine from aqueous solution by simple and chemically treated biosorbents was studied and the results were shown in Fig. 5. From this figure, it was found that the adsorptive quantity of the dye on all the types of adsorbent almost remained constant and equilibrium was nearly reached after $1 \mathrm{~h}$. The adsorption efficiency, however, was maximum for every point in case of U.T.B.This delayed adsorption trend suggests that physiosorption is operative in adsorbing dye ions on biomass, because chemisorption occurred relatively faster than physiosorption. Physiosorption is generally dominant at low temperature and characterized by a relatively little energy of adsorption ${ }^{28}$. Hence, in the present experiment, $1 \mathrm{~h}$ was chosen as the equilibrium time.

Adsorbate pH: The $\mathrm{pH}$ is an important parameter affecting the rate and extent of adsorption. Variation of $\mathrm{pH}$ may alter the solubility of ions and surface charge of biosorbent. The effect of $\mathrm{pH}$ on adsorption of Indigo caramine dye by Citrus reticulata peels is given in Fig. 6 . The maximum dye sorption occurred at $\mathrm{pH} \mathrm{1-2} \mathrm{in} \mathrm{all} \mathrm{cases} \mathrm{and} \mathrm{decreased}$

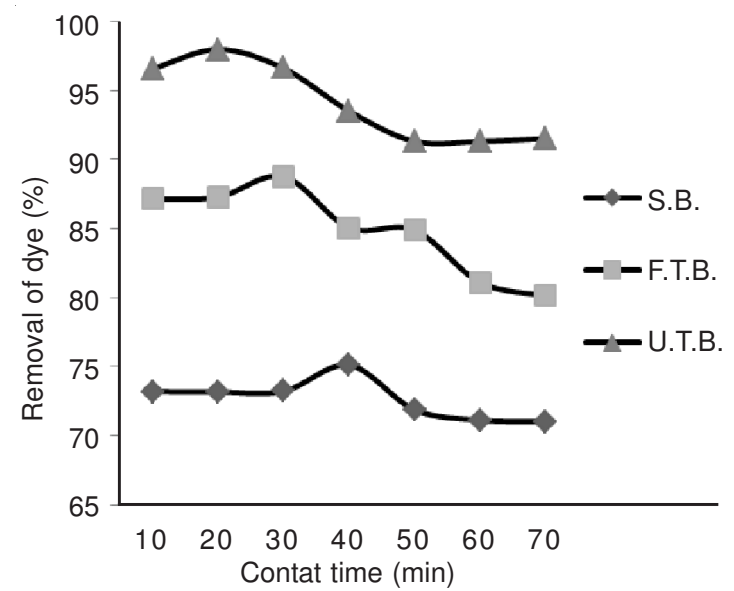

Fig. 5. Effect of contact time on adsorption of Indigo carmine by Citrus reticulata peels

thereafter. Acidic dyes are more ionized in lower $\mathrm{pH}$ range, which results in larger concentration of ionized species in aquatic medium that can interact more with active binding sites of biosorbent. Indigo carmine is an acidic/anionic dye. In basic conditions, the number of negatively charged active sites on biosorbent surfaces increases, which hindered in adsorption of anionic dye because of electrostatic repulsion. Usually acidic dyes adsorption is much higher in acidic solutions rather than those in high $\mathrm{pH}$ conditions ${ }^{28,29}$.

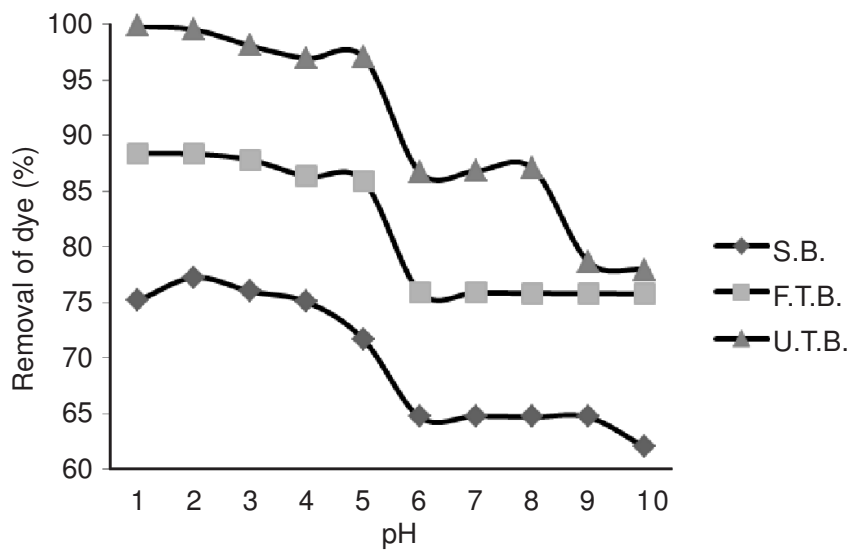

Fig. 6. Effect of $\mathrm{pH}$ on adsorption of Indigo carmine by Citrus reticulata peels

Adsorbent dosage: The experiment on the influence of adsorbent dosage on adsorption of the dye was done with different dosages. The graph is shown in Fig. 7. Maximum adsorption occurred when adsorbent dose is 1.5, 0.6 and $0.6 \mathrm{~g}$ using S.B, F.T.B and U.T.B, respectively. But urea treated biosorbent

TABLE-1

FT-IR SPECTRAL ANALYSIS OF SIMPLE (S.B), FORMALDEHYDE TREATED (F.T.B) AND UREA TREATED (U.T.B) Citrus reticulate PEELS

\begin{tabular}{|c|c|c|c|}
\hline Functional groups vibrational assignments & S.B $\left(\mathrm{cm}^{-1}\right)$ & F.T.B $\left(\mathrm{cm}^{-1}\right)$ & U.T.B $\left(\mathrm{cm}^{-1}\right)$ \\
\hline N-H stretching (amido, amino groups) & - & - & 3791.2 \\
\hline OH stretching (hydroxyl, carboxyl group) & 3416 & 3429 & - \\
\hline C-H stretching (methyl, methylene group in lignin) & 2921.01 & 2918 & 2629.8 \\
\hline $\mathrm{C}=\mathrm{O}$ and $\mathrm{C}=\mathrm{C}$ stretching (carbonyl of aldehyde/ketone) & 1639 & 1627 & 1695.0 \\
\hline $\mathrm{C}-\mathrm{H}$ bending & 1434.7 & 1371 & $1459.3,1375.5$ \\
\hline C-O-C stretching (ether group in carbohydrates) & 1049 & 1055.7 & 1057.1 \\
\hline $\mathrm{O}=\mathrm{C}-\mathrm{N}$ bending & - & - & 548.4 \\
\hline
\end{tabular}




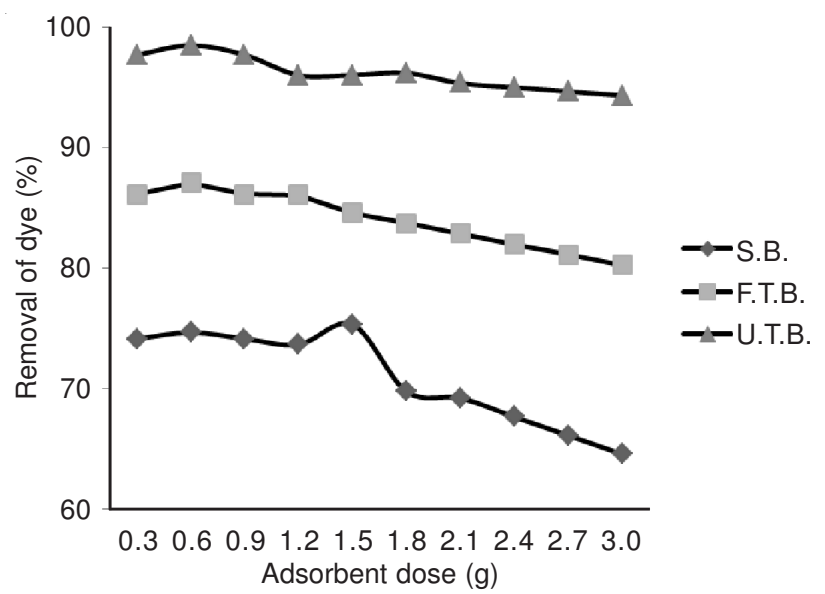

Fig. 7. Effect of adsorbent dose on adsorption of Indigo carmine by Citrus reticulata peels

adsorb more as compared to simple and formaldehyde treated biosorbents.Amount of available adsorption sites increased with a rise in adsorbent dosage and resulted in better adsorption. After optimized value, decrease in adsorption capacity may be due to the decline in solute transfer rate on biosorbent surface. In literature, a decrease was found in the adsorption efficiency by many researchers, when the adsorbent dose was increased. They suggested that a limited cell accumulation taking place at high adsorbent dose caused reduction of active sites. Various explanations including $\mathrm{pH}$, ionic strength, temperature and dye ions in solution had been suggested to elucidate the reduced adsorption capacity at increasing biomass ${ }^{16,22}$.

Temperature: Its effect on the adsorption of dyes is very important on large scale application of adsorption as various effluents are produced at quite high temperatures. The adsorption of Indigo caramine dye was investigated as a function of temperature and graphically represented in Fig. 8. Maximum adsorption was obtained at nearly $30^{\circ} \mathrm{C}$ in case of S.B, while F.T.B showed maximum value at $60^{\circ} \mathrm{C}$, suggesting that adsorption between the dye and F.T.B was an endothermic process. Adsorption efficiency nearly remained constant in case of U.T.B. The negligible decrease with further increase in temperature in case of S.B and U.T.B due to the decreased surface activity suggesting that adsorption in this case became an exothermic process. In that case, the mechanism was mainly physiosorption. It was further confirmed from isothermal investigations ${ }^{26}$.

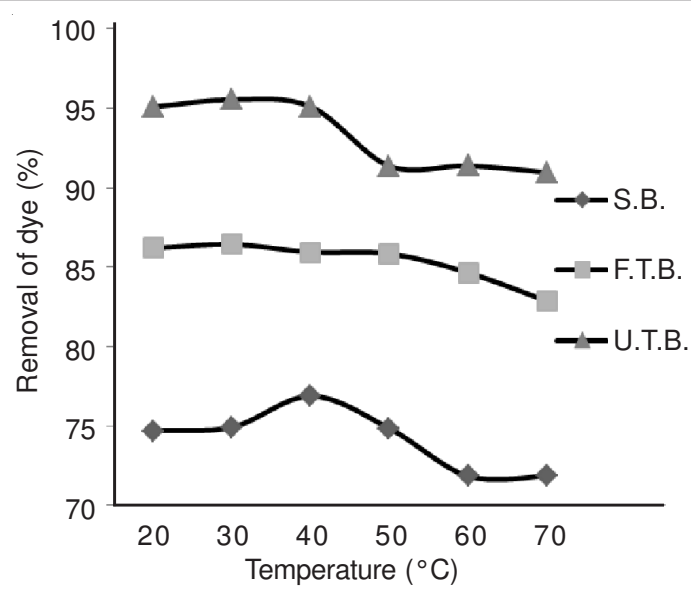

Fig. 8. Effect of temperature on adsorption of Indigo carmine by Citrus reticulata peels

Determination of mechanism of adsorption and feasibility of process: Table- 2 shows the Langmuir isothermal parameters while Table- 3 shows the Freundlich isothermal parameters for Indigo carmine dye adsorption by Citrus reticulata peels. Correlation coefficient values comparison indicated that Freundlich model is applicable more to adsorption data using simple (S.B) and formaldehyde treated biosorbents (F.T.B), while Langmuir model is followed using urea treated biosorbent (U.T.B). It means physio-sorption is the main mode of adsorptive removal of Indigo carmine dye by Citrus reticulata peels, when S.B and F.T.B were used, while chemisorption occurred more using U.T.B.Langmuir maximum adsorption capacity parameter ' $\mathrm{q}_{\mathrm{m}}$ 'values are: 5.90, 14.79 and $71.07 \mathrm{mg} \mathrm{g}^{-1}$ for S.B, F.T.B and U.T.B, respectively. These values indicated that urea treatment is more effective for chemical treatment, as compared to formaldehyde treatment. This is also evident from previous Figs. 4-7. Freundlich physiosorption constant ' $\mathrm{K}_{\mathrm{F}}$ 'values are: $35.27,77.90$ and $26.41 \mathrm{mg}^{1-1 / n} \mathrm{~L}^{1 / n} \mathrm{~g}^{-1}$ for S.B, F.T.B and U.T.B, respectively. They indicated that formaldehyde treatment is more effective for physiosorptive removal of dye, because formaldehyde dissolves colouring matter and resinous material of Citrus reticulata peels, which results in exposure of more binding sites.

Langmuir parameter ' $b$ ' is used to determine separation factor ' $\mathrm{R}_{\mathrm{L}}$ ' and thermodynamic parameter ' $\Delta \mathrm{G}^{\mathrm{o}}$ '. Feasibility of using Citrus reticulata peels for adsorption of Indigo carmine

TABLE-2

LANGMUIR ISOTHERMAL AND THERMODYNAMICAL PARAMETERS FOR ADSORPTIVE REMOVAL OF INDIGO CARMINE DYE BY CHEMICALLY MODIFIED Citrus reticulate PEELS

\begin{tabular}{|c|c|c|c|c|c|c|c|}
\hline \multirow{2}{*}{ Biosorbent } & \multicolumn{5}{|c|}{ Langmuir isotherm parameters } & \multirow{2}{*}{$\begin{array}{l}\text { Separation } \\
\text { factor } \mathrm{R}_{\mathrm{L}}\end{array}$} & \multirow{2}{*}{$\begin{array}{l}\text { Thermodynamic parameter } \\
\qquad \Delta \mathrm{G}^{\mathrm{o}}\left(\mathrm{KJ} \mathrm{mol}^{-1}\right)\end{array}$} \\
\hline & Slope & Intercept & $\mathrm{R}^{2}$ & $\mathrm{q}_{\max }\left(\mathrm{mg} \mathrm{g}^{-1}\right)$ & $\mathrm{b}\left(\mathrm{L} \mathrm{g}^{-1}\right)$ & & \\
\hline S.B & 0.153 & -0.169 & 0.758 & 5.90 & 1.108 & 0.018 & 0.254 \\
\hline F.T.B & 0.052 & -0.068 & 0.714 & 14.79 & 1.289 & 0.016 & 0.629 \\
\hline U.T.B & 0.045 & -0.014 & 0.875 & 71.07 & 0.312 & 0.069 & -2.886 \\
\hline
\end{tabular}

TABLE-3

FREUNDLICH PARAMETERS FOR ADSORPTIVE REMOVAL OF INDIGO CARMINE DYE BY CHEMICALLY MODIFIED Citrus reticulate PEELS

\begin{tabular}{|c|c|c|c|c|c|}
\hline \multirow{2}{*}{ Biosorbent } & \multicolumn{5}{|c|}{ Freundlich isotherm parameters } \\
\hline & Slope & Intercept & $\mathrm{R}^{2}$ & $\mathrm{~K}_{\mathrm{F}}\left(\mathrm{mg}^{1-1 / \mathrm{n}} \mathrm{L}^{1 / \mathrm{n}} \mathrm{g}^{-1}\right)$ & $\mathrm{n}$ \\
\hline S.B & 2.223 & 1.547 & 0.834 & 35.27 & 0.450 \\
\hline F.T.B & 1.745 & 1.892 & 0.698 & 77.90 & 0.573 \\
\hline U.T.B & 1.019 & 1.422 & 0.861 & 26.41 & 0.981 \\
\hline
\end{tabular}


dye were confirmed by separation factor values, ' $\mathrm{R}_{\mathrm{L}}$ ', which are in between zero to unity, i.e.: 0.018, 0.016 and 0.069 for S.B, F.T.B and U.T.B, respectively. Negative value of Gibb's free energy $\left(\Delta \mathrm{G}^{\mathrm{o}}\right)$ indicated that urea treated Citrus reticulata peels are more suitable for adsorption of Indigo carmine dye from water. Freundlich constant 'n'values smaller than eight, indicated the practicability of this process at minor concentration of dye $\mathrm{e}^{26-29}$.

\section{Conclusion}

The application of indigenous waste materials from agricultural residues as economical substitution to commercial adsorbents has been demonstrated in this study. This research work indicated that Citrus reticulata peels can be effectively used for adsorptive removal of Indigo carmine dye from water. Their adsorption capacity is further enhanced by treating them with formaldehyde and urea separately. Results shown that urea treatment of Citrus reticulata peels was more effective for removing anionic dyes from water. Maximum removal of dye by simple, formaldehyde treated and urea treated Citrus reticulata peels were: $5.90,14.79$ and $71.07 \mathrm{mg} \mathrm{g}^{-1}$, respectively. So, it is concluded that urea treated Citrus reticulata peels can be used on industrial scale for removal of Indigo carmine dye.

\section{REFERENCES}

1. N. Mohan, N. Balasubramanian and C.A. Basha, J. Hazard. Mater. 147, 644 (2007).

2. M.K. Sharma and R.C. Sobti, Mutat. Res.-Genetic Toxicol. Environ. Mutagen., 465, 27 (2000).

3. R. Malik, D.S. Ramteke and S.R. Wate, Waste Manage., 27, 1129 (2007).

4. K. Kadirvelu, M. Kavipriya, C. Karthika, M. Radhika, N. Vennilamani and S. Pattabhi, Bioresour. Technol., 87, 129 (2003).

5. A.R. Dinçer, Y. Günes, N. Karakaya and E. Güne, Bioresour. Technol. 98, 834 (2007).
6. D. Shen, J. Fan, W. Zhou, B. Gao, Q. Yue and Q. Kang, J. Hazard. Mater., 172, 99 (2009).

7. M.S. Chiou, P.-Y. Ho and H.-Y. Li, Dyes Pigments, 60, 69 (2004).

8. M.T. Sulak, E. Demirbas and M. Kobya, Bioresour. Technol., 98, 2590 (2007).

9. K.P. Sharma, S. Sharma, S. Sharma, P.K. Singh, S. Kumar, R. Grover and P.K. Sharma, Chemosphere, 69, 48 (2007).

10. S. Sen and G.N. Demirer, Water Res., 37, 1868 (2003).

11. N. Modirshahla, A. Hassani, M.A. Behnajady and R. Rahbarfam, Desalination, 271, 187 (2011).

12. N. Daneshvar, H. Ashassi-Sorkhabi and A. Tizpar, Sep. Purif. Technol., 31, 153 (2003).

13. H. El-Boujaady, A. El-Rhilassi, M. Bennani-Ziatni, R. El-Hamri, A. Taitai and J.L. Lacout, Desalination, 275, 10 (2011).

14. P. Leechart, W. Nakbanpote and P. Thiravetyan, J. Environ. Manage., 90, 912 (2009).

15. M. Valix, W.H. Cheung and G. McKay, Chemosphere, 56, 493 (2004).

16. M.M. Dávila-Jiménez, M.P. Elizalde-González and V. HernándezMontoya, Bioresour. Technol., 100, 6199 (2009).

17. M.A. Behnajady, N. Modirshahla and R. Hamzavi, J. Hazard. Mater, 133, 226 (2006).

18. J.L. Wang and J.Z. Wang, J. Hazard. Mater, 143, 2 (2007).

19. X. Zhang, F. Zhao and K.A. Li, Microchem. J., 68, 53 (2001).

20. Y.R. Sheynkin, C. Starr, P.S. Li and M. Goldstein, Urology, 53, 214 (1999).

21. F.V. de Andrade, G.M. de Lima, R. Augusti, M.G. Coelho, J.D. Ardisson and O.B. Romero, Chem. Eng. J., 180, 25 (2012).

22. S. Liang, X. Guo, N. Feng and Q. Tian, J. Hazard. Mater, 170, 425 (2009).

23. P. Velmurugan, V.R. Kumar and G. Dhinakaran, Int. J. Environ. Sci., 1, 1492 (2011).

24. M. Arami, N.Y. Limaee, N.M. Mahmoodi and N.S. Tabrizi, J. Colloid Interf. Sci., 288, 371 (2005).

25. R. Rehman and T. Mahmud, Proceeding of ICENV, Penang, Malaysia, p. 103 (2012).

26. F. Kanwal, R. Rehman, J. Anwar and M. Saeed, Asian J. Chem., 25, 2399 (2013).

27. A. Mittal, J. Mittal and L. Kurup, J. Hazard. Mater, 137, 591 (2006).

28. S.M. de Oliveira Brito, H.M.C. Andrade, L.F. Soares and R.P. de Azevedo, J. Hazard. Mater., 174, 84 (2010).

29. U.R. Lakshmi, V.C. Srivastava, I.D. Mall and D.H. Lataye, J. Environ. Manag., 90, 710 (2009). 